\title{
C-E Translation of Public Signs at the Ten-Mile Liquor City from the Eco-Translatology Perspective
}

\author{
Hongying Li, Pengju Li \\ School of Economics, Sichuan University of Science \& Engineering, Zigong, China \\ Email: lihongying314@163.com
}

How to cite this paper: $\mathrm{Li}, \mathrm{H}$. Y., \& Li, P. J. (2019). C-E Translation of Public Signs at the Ten-Mile Liquor City from the EcoTranslatology Perspective. Chinese Studies, $8,103-114$

https://doi.org/10.4236/chnstd.2019.83009

Received: July 17, 2019

Accepted: August 23, 2019

Published: August 26, 2019

Copyright (อ 2019 by author(s) and Scientific Research Publishing Inc. This work is licensed under the Creative Commons Attribution International License (CC BY 4.0).

http://creativecommons.org/licenses/by/4.0/

\begin{abstract}
Flaws widely exist in the English translation of the public signs at the Ten-mile Liquor City, such as lack of translation, grammar mistakes, spelling mistakes, misuse of words disagreement in translation, semantic fault, wordiness, etc., which not only brought inconvenience for foreign tourists but also ruined the image of the scenic area. This article recommended references from the eco-translatology perspective, with a hope to rouse more scholars' attention to improve the English translation of the public signs at the Ten-mile Liquor City.
\end{abstract}

\section{Keywords}

C-E Translation, Public Signs, Ten-Mile Liquor City, Eco-Translatology

\section{Introduction}

Wuliangye Group Co., Ltd. is situated on the bank of Minjiang River, north of Yibin City in Sichuan Province, known as the "First Major City along the Yangtze River". Wuliangye Liquor, is an outstanding representative of strong aromatic liquor in China, with its own unique liquor style, featuring lasting flavors, mellow savor, luscious and refreshing tastes, harmonious and just-right flavors, and especially famous for its versatile flavors. In 2018, about 8,639,000 foreign visitors came to Sichuan for traveling. Ten-mile liquor City, as the only the industry scenic area in Yibin and one of the national AAAA level scenic areas in Sichuan Province, has attracted thousands of foreign visitors. It is also with the responsibility to propagandize the corporate culture and Sichuan liquor culture. Public signs there play an essential role in providing guidance and information for visitors and are regarded as the window through which foreign 
visitors start to know Wuliangye and its liquor culture. Recently, Yibin city is endeavoring to construct international city and international tourist destination and the Wuliangye Ten-mile Liquor City is also devoting itself to build AAAAA scenic area. However, little attention has been paid to the Chinese-English translation of the public signs that flaws widely exist in the English translation of public signs, which has ruined the image of the scenic area and the city. This paper aims to take a systematic analysis on the C-E translation of public signs at the Ten-mile liquor City from the eco-translatology perspective by revealing the remarkable flaws in C-E translation of the public signs and coming up with specific countermeasures.

\section{Literature Review}

\subsection{Public Signs}

Dai Zongxian and Lv Hefa defined the public signs as what are shown publicly offering warning, direction, notification and other information (Dai \& Lv, 2005). He Xueyun concluded that the public signs are special style intended to show special information to specific groups to ensure the realization of some specific communication purpose (He, 2006). During the past 20 years, different Chinese scholars have defined public signs in different ways. However different are the definitions, public signs mainly refer to the billboard, notification bar, signpost, shop sign and introduction in scenic spots (Luo, 2006; Lv, 2017a; Ding, 2006; Liu, 2008).

\subsection{Previous Studies on Public Signs Translation}

Regarding the content, previous studies on the public sings can be classified into the groups as follows:

1) Translation strategies, principles and methods

Theoretical study on public signs in China started from the introduction of the foreign translation strategies. Guo Jianzhong discussed the cultural elements in translation and analyzed the translation principles of adaptation and alienation (Guo, 1998). After then, scholars started to apply adaptation to the translation of public signs. In 1999, Guo Jianzhong summarized the main popular translation theories, principles and methods put forward by American scholars, such as Herbert Cushing Tolman and C.H. Conley. Nida's language universality, message of translation, theory of readers' response and dynamic equivalence had great impact on the practice of literature and public signs translation. Liu Fagong proposed three principles for public signs translation, namely concise, consistency and comprehensibility on the basis of Newmark's text typology (Guo \& $\mathrm{Xu}$, 1999) Ding Hengqi concluded 5 "Cs" to summarize the characteristics of appropriate English public signs, namely concise, conventional, consistent, conspicuous and convenient, respectively (Ding, 2006).

However, after 2005, the study on translation strategies boomed. And some scholars started to confused translation strategies with translation methods and 
translation techniques. Thus, Xiong Bing made a through illustration on the definition, the features and their relationship of the three terms (Xiong, 2014).

2) Case studies on the existing translation problems of Chinese public signs After 2005, more academic researches and articles on the translation of Chinese public signs are published. Some famous scholars, such as Lv Hefa, Guo Jianzhong He Xueyun and Dai Zongxian also paid attention to the translation of public signs. They didn't just point out the translation problems but also analyze the causes of these mistranslation or mistakes (Dai \& Lv, 2005; He, 2006; Luo, 2006; Ding, 2006; Liu, 2008; Lv, Jiang, \& Zhou 2015). The translation of public signs in some well-known scenic areas or spots in China improved a lot owing to the contribution of these scholars.

3) Linguistic features of public signs

Public signs in the scenic area fall into two categories according to the internal attribute of their content, namely scientific and touristic. In terms of the function, public signs can be divided into five groups: indicative, reminding, restricting, forbidden and descriptive (Lv, Jiang, \& Zhou 2015). Scientific public signs are usually descriptive and indicative, aiming to provide basic information and guidance for the tourists, focusing on the education aspect.

However, touristic public signs are widely used to tell stories about the poems and calligraphies preserved at the scenic spots.

In terms of the sentence structure, Chinese touristic public sign are composed of neat verses or balanced sentences cited from the ancient poems to ensure the wording keep in line with traditional expressing to maintain aesthetic value in tone, form and meaning. For English public signs, the wording sticks to the theme, with objective description and popular expression, focusing on the accuracy and practicality (Chen, 2006).

4) The construction of translation corpus of public signs

With the increasing and deepening exchange between China and foreign counties, tourism boomed in recent years in major cities local governments started to realize the significance of appropriate translation of public signs. The corpus of C-E translation of public signs contributes to constructing a highly satisfactory language and cultural environment in cities and scenic areas in their endeavor of building international cities and tourist destinations (Chen, 2006). Lv Hefa published article on the classification of signs of one million words, in which he provided comparative corpus and a parallel corpus, offering references for governments of different levels and practitioners of translation services (Lv, Jiang, \& Zhou, 2015).

\subsection{Previous Study on Public Signs Translation at the Ten-Mile Liquor City}

Practical study on the public signs translation at the Ten-mile liquor City is rare. Only Li Hongying discussed the problems in the English translation of the public signs at this scenic area and put forward relevant countermeasures. The flaws in the English translation of the public signs at the Ten-mile liquor City mainly 
include lack of translation, grammar mistakes, spelling mistakes, disagreement in translation, semantic fault, wordiness. Countermeasures to settle the problems are concluded as follows: adopting existing translation, abiding by translation principles and adopting translating strategies flexibly, improve the translator's ability and improve the management level of relevant administration departments (Li, 2018). Although Li Hongying's study pointed out the problems and put forward countermeasures, one of its limitations is the lack of scientific theory guidance. In this paper the eco-translatology was adopted as the theoretical foundation to conduct further research on the English translation of public signs.

\section{Theoretical Foundation}

\subsection{Eco-Translatology}

Eco-translatology is a new interdisciplinary approach for translation studies first proposed by Professor Hu Gengshen with reference to the Darwin's evolution theory. This theory aims to describe and interpret translation from an ecological perspective ( $\mathrm{Hu}, 2008)$. In his theory, Professor $\mathrm{Hu}$ emphasized the importance of translator's adaptation and selection activities in a translation eco-environment, and pointed out that adaptation and selection could be viewed as the translator's instinct as well as the essence of translating ( $\mathrm{Hu}, 2004$; Lv, 2017b).

\subsection{Elements in Eco-Translatology}

1) Translational eco-environment

Translational eco-environment refers to the worlds of source text and the target languages, comprising the linguistic, communicative, cultural and social aspects of translating, as well as the author, the client and the readers ( $\mathrm{Hu}, 2004)$. Thus, under this premise, the translation process is defined as a selection activity of the translator's adaptation to fit the translational eco-environment.

2) Adaptation and Selection

Professor Hu first officially used the principles of nature selection to explain the translation process: translation should be considered as a series of the translator's adaptation and selection activities (Hu, 2004). Translation as adaptation and selection defines the translation as a selection activity of the translator's adaptation to fit the translational eco-environment.

3) Translator-centeredness

$\mathrm{Hu}$ Gengshen proposed that the translator is both the reader of the original text and the writer of the source text (Hu, 2004). However, either as the reader or as the writer, the translator is assigned specific task-to conduct the translation with explicit purpose. The core ideology of Eco-translatology should be "translator-centeredness". From the perspective of the relation among different parties involved in the translation process, the translator plays such specific role and function that he can't be replaced by other parties. Regarding the function, the translation works both as a reader and a writer. As the reader of the original 
text, the translator is supposed to understand the original text thoroughly, while as the writer, the translator should be able to deliver the correct information in a proper way.

4) Multi-dimensional adaptation and adaptive selection

Based on the multi-dimensional adaptation principles, $\mathrm{Hu}$ Gengshen put forward translation methods for translation as adaptation and selection: the Transformation of linguistic dimension, communicative dimension and cultural dimension ( $\mathrm{Hu}, 2004)$. Linguistic dimension mainly refers to the form of language, especially the rhetorical styles and techniques. The Transformation of cultural dimension is the toughest one. Therefore, the translator is required to keep intercultural communication in mind to overcome the culture barriers and ensure the realization of information communication. For the adaptive selection of the communication dimension, it requires the translator to focus on the communication level to find out whether the communication intention is shown in the targeted text.

\section{Problems in the Translation of Public Signs at the Ten-Mile Liquor City}

Li Hongying has discussed the flaws in the English translation of the public signs at the Ten-mile liquor City (Li, 2018). Based on the previous study and extensive field research, we collected up-dated data on the English version of public signs at the Ten-mile Liquor City, and sum up in problems as follows.

1) No translation

There are about ten major scenic spots at the Ten-mile Liquor City. However, only small portion of public signs at these spots were translated into English. Even at the liquor culture museum, where the history of the company and the fermenting process of Wuliangye are introduced, the English public signs are rare. It is inconvenient for English speakers to know the company and the Wuliangye liquor making process.

2) Grammar mistake

Grammar mistakes are common in the translation of public signs at the Ten-mile Liquor City, including the misuse of articles (such as a hour), the disagreement of subject and predicate (such as The 225 steps up to top is called the steps to holy mountain), confusion on singular and plural (such as Staffs Only), the misuse of preposition (such as Stand at the right) and wrong tense (such as it is awarded the best liquor).

3) Misuse of word

For most English words, they have multiple meaning, and the meaning of the words probably vary from the forms. Take park for example, as a noun, it means an area of public land in a city where people can go for a walk, while it means leave a vehicle in a particular place for a period of time as a verb. When a public signs indicates visitors should not leave their cars at some place, it should be No Parking rather than No Park. 
4) Disagreement in translation

On different signposts, the names of the famous scenic spots at the Ten-mile liquor city differ from each other. For example, the name of the scenic area was translated into "Ten mile wine city", "Ten-li liquor city" and "Ten miles liquor city", respectively. The famous mountain at the scenic area was translated into "Jiusheng Mountain", "Mount. Athos Wine" and "Wine Master Mountain". A spring also has two translations, "Spring of Eternal Peace" and "Peace Fountain". The same spot is entitled with different names, which no doubt confuses many foreign tourists.

5) Semantic fault

The styles of Eglish can be formal and informal. In the translation of Public signs, translators should avoid to use informal English, such as Look out should be replaced by Caution or Mind. In the introduction to the product, the translator applied Wuliangye First Distinguished to describe the fact that Wuliangye was first introduced to abroad and got its fame. In fact, there is its counterpart in English, Cut a brilliant figure.

6) Wordiness

Wordiness means too many words were used in a translation. A tip at one scenic spots says "Do not play around the water to avoid dropping into the deep water", which is obviously wordy and should be revised into "No Wading, Deep Water".

To better overcome these problems and improve the translation of public signs at the Ten-mile Liquor City, this paper chose eco-transtology to discuss how to make the translator further adapt to the eco-environment at the scenic area and better select the targeted language so as to ensure the readers a deeper understanding of the public signs.

\section{Eco-Translatology in the English Translation of Public Signs at the Ten-Mile Liquor City}

\subsection{Eco-Environment of Public Signs at the Ten-Mile Liquor City}

To study the translation of public signs from eco-translatology perspective, it is necessary to hold a clear view of the eco-environment of the public signs at the Ten-mile Liquor City.

1) Source text

Like most Chinese public signs, signs at the Ten-mile Liquor City are endowed with directing, prompting, restricting and compelling functions. The remarkable characteristics of the Chinese public signs, especially for those introducing the history of a place of interest, are the abundant application of parallel sentences or Chinese four-character idioms. For public signs at the at Ten-mile Liquor City, many of them are related to the process of making liquor, the tradition and history of Wuliangye, the convention of liquor drinking in different minorities, which endows the relevant public signs at the Ten-mile Liquor City with remarkable professional characteristics. 


\section{2) Target language}

For the target language, English public signs are featured by frequent use of nouns, verbs, gerunds, phrases, abbreviation, combination of words and signs, present tense and imperative structure (Lv, 2017b). Ordinary public signs usually combine words and signs, and the main function of the words is to explain, supplement and clarify the signs, such as what we see in the traffic signs. English public signs with present tense and imperative structure are intended to indicate, remind or restrict reader to do or not to do something. Anyway, translators should put conciseness and accuracy in the first place when translate the Chinese public signs into English ones.

3) People involved

At the Ten-mile liquor city, people involved in the translation eco-environment mainly include the translator, the reader/visitor and the maker of the public signs billboards. For English public signs at the Ten-mile liquor City, besides foreign visitors, the reader also include Chinese visitors who can read and speak English or those who want to study English.

\subsection{Translator's Adaptation}

\subsubsection{The Translator's Adaptation to Personal Need}

According to Abranhem Maslow's hierarchy of needs, our needs can be divided into five levels: physiological need, safety need, love/belonging need, esteem need and self actualization. The need of the translator will influence the translation result. For some translator, probably they live off translation. While some do translation because they have passion on this work. For those who are occupied in translation to contribute to the culture communication and the development of the human civilization, self actualization will be their ultimate needs. Therefore, in the translation process, the self-realization has been driving the translator to pursue an optimal translation.

When the translator encounter some unfamiliar terms during the translation process, like "Daqu" and "Xiaoqu", they have two choices. One is to find out the specific professional meaning of the term. The other is just to translate them based on the translator's experience and knowledge. If the translator just wants to finish the translation task, he is likely to use Chinese Bopomofo "Daqu" directly. But, if the translator has higher need to realize self-esteem, probably he will add more explanation to this term, like "Daqu" is one kind of starter used to make distilled liquor, while "Xiaoqu" is another starter used to make Shaoxing wine.

\subsubsection{Adaptation to the Translator's Competence and Ability}

The second aspect of the translator's adaptation lies on the adaptation to his own competence and ability, which is adaptation to the translator's inner factors. In order to ensure the translation quality, the translator should accept the assignment on which they have enough confidence to accomplish, which means the translator should adapt to his own competence and ability, since each translator 
has unique translation style, feeling tone and creation characteristic ( $\mathrm{Hu}, 2004)$. The Prose Poem to Wuliangye is composed to reveal the special liquor history and culture of the Wuliangye Group. The translation of the Prose Poem to $\mathrm{Wu}$ liangye requires not only high English level but also profound Chinese cultural background. Not any translator can finish the assignment. Even those professors who have engaged in translation teaching for many years are still reluctant when being invited to finish this task. That's why there is still no English version of this poem now.

\subsubsection{Adaptation to Translational Eco-Environment}

Finally, the translator has to adapt to the translational eco-environment, which is the external factors. As aforementioned, translational eco-environment comprises of source text and the target languages and the people involved. Translator needs to remind himself of the function of different public signs and the characteristics of the targeted language.

Most billboards at the Wuliangye liquor cultural museum lack of English translation, which brings inconvenience for foreign visitors. Even though some introduction to the company has been translated into English, it is so hard for the foreign visitors to understand what the translator intended to say. For example, in English, when an award is presented to someone or a company, it is common to use expression like $X X$ award is presented to $X X$ in recognition of $X X$ in $X X$. However, at this scenic area, wording like The State Quality Administration Award (Figure 1(a)) is used to introduce the awarding of the company, without further explanation about what is the quality administration. To improve the quality of the translation, wording like $\mathrm{An} A$ ward is Presented to $\mathrm{Wu}$ liangye in Recognition of Its Outstanding Administration in Quality is recommended.

Considering the limited space on the billboard, the translator also has to take the maker of public signs billboards into account, which requires the translator to choose words or phrases as simple and concise as possible to ensure that enough space can be reserved. For example, the English translation in Figure 1 (b) is so wordy that small space is left to the maker of the billboard. Meanwhile, it failed to rouse readers' attention at the first time. According to the translation rule of conciseness, the English translation should be Caution! Deep Water!

\subsection{Translator's Selection}

During the process of adaptation to the eco-environment, translator needs to select proper target language to accomplish the transformations of linguistic dimension, communicative dimension and cultural dimension, which is the toughest part.

1) Transformation of linguistic dimension

The essence of translation can be concluded as the transition of different levels, both referring to the voice and characters and cultural information. The transition must comply with some standards. To adapt to the linguistic dimension, 

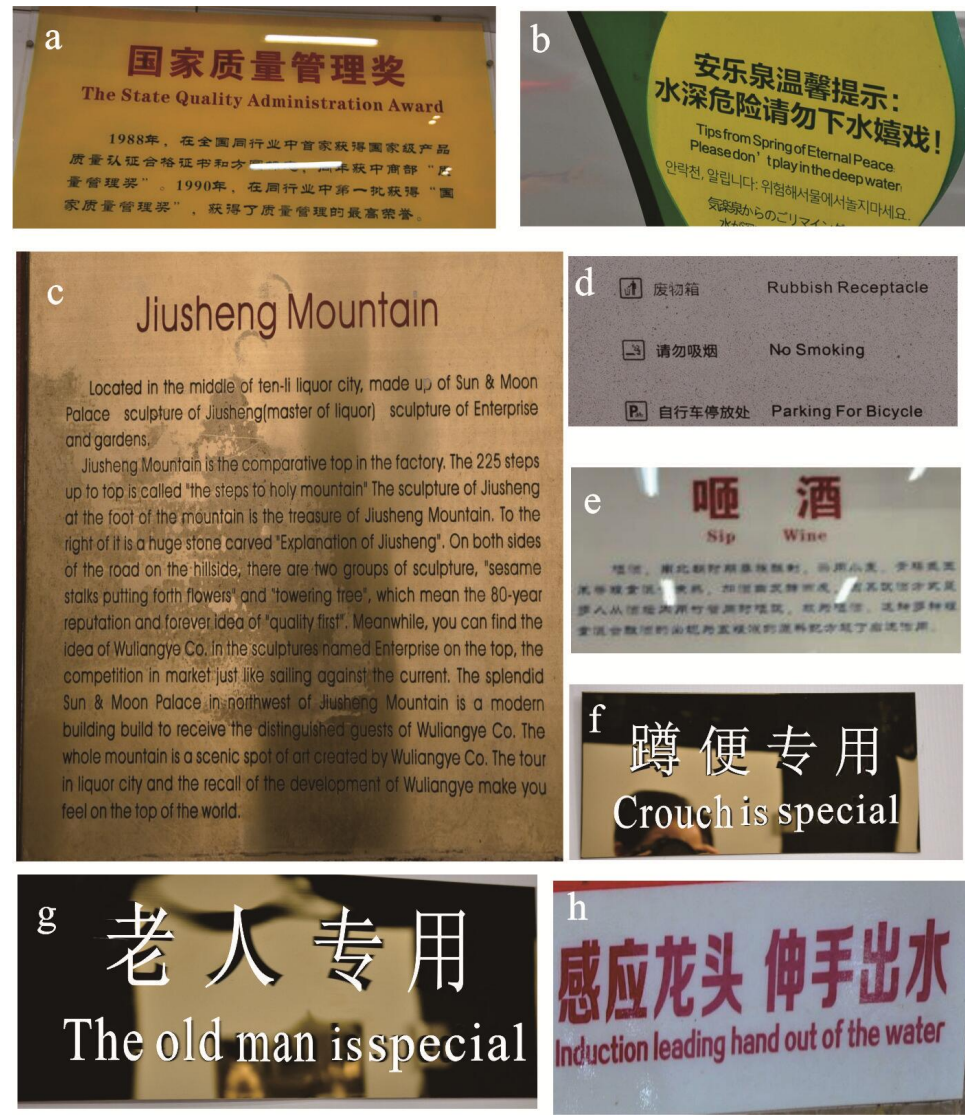

Figure 1. Chinese and English public signs at the ten-mile liquor city.

the translator is required to pay attention to the language style, wording and phrasing, and sentence structure, etc. Only in this way, can the translator finish the transition of culture dimension. However, at the Ten-mile Liquor City, too many problems or flaws occurred in the English translation of public signs due to the failure of the linguistic dimension, which can be ascribed to the lack of knowledge on English grammar, poor spelling and confusion on the usage of Chinese Bopomofo.

As Figure 1(c) shows, at the Jiusheng Mountain, an introduction to the scenic spot with wording like "The 225 steps up to top is called the steps to holy mountain" is typical grammar mistake with disagreement between the subject and verb. In the sentence, there are two groups of sculpture, sculpture should be replaced by its plural. In the sentence, the splendid Sun \& Moon Palace in northwest of Jiusheng Mountain is a modern building build to receive the distinguished guests of Wuliangye Co. the prep in should be changed into at, and the definite article should follow at and build should be replaced by its past participle. Besides, improper use of Chinese Bopomofo has little contribution to the communication and often confuses the readers. For example, Jiusheng in Chinese refers to the person who has the power to bless the liquor-making process successful. Direct use of Jiusheng Mountain as the name of the scenic spot can't reveal its cultural significance, thus it should be replaced with Liquor Saint 
Mountain. In Figure 1(d), Rubbish Receptacle should be replaced by Dustbin to adapt to the target language. Parking for bicycles indicates a place where to park the bikes, thus it should be replaced by Parking lot for bicycles.

2) Transformation of cultural dimension

During the translation process, more attention should be paid to the delivery of cultural connotation. A qualified translator should acquaint himself with both the domestic and foreign cultures and keep sensitive to the cultural discrepancies. The failure of transformation can be owed to the inappropriate transformation of thought and cultural connotation.

In Figure 1(c), the scenic area is named Ten-li liquor city. As we all know that $l i$ is a length unit used just in China that most foreigners don't know what $l i$ stands for. In European countries, they adopt the metric system. And mile is widely used when talking about distance. Hence, we recommended the name of the scenic area should be Ten-mile Liquor City.

There is a sign with "sip wine" without English translation at the museum of Wuliangye (Figure 1(e)). It is hard to understand what sip wine is since there is no counterpart in English, so it is necessary for the translator to explain the drinking process in detail to help foreign tourists understand it. In some minorities, such as Miao, Qiang, and Tujia in Sichuan province, there is a special drink habit "Sip liqour" "Sip liqour" is not liquor per se, but a drinking habit. Thus we can use description like "Sip liquor" is kind of drinking habit prevalent in several minorities in Sichuan. When entertain the guests, the host will serve them with a bottle of liquor. All the guests need to sip the liquor from the bottle with a bamboo or reed straw then pass it onto the next one. The bottle will be fulfilled with water after a round till the liquor tastes bland (Li, 2018).

3) Transformation of communicative dimension

The translation aimed to deliver information that can overcome language and cultural obstacles and to get communication realized. In other words, the function of public signs at the scenic areas concentrated on its information and appealing function (Zhang, 2017). Lacking of translation, grammar mistakes, spelling mistakes, disagreement in translation and semantic fault have profound negative impacts on the realization of communication. As Figures $1(\mathrm{f})-(\mathrm{g})$ show, English public signs at the toilet sound ridiculous. Although special is also defined as used by or intended for one particular person or group of people in the oxford advanced learner's English-Chinese dictionary, when using this meaning, this word should be used as adjective before a noun. Since these English signs occur at the toilet, they are intended to remind the users that the toilet should be used by particular persons. Therefore the English translation should be replaced by Squatting pan and The Elder only, resepenctively. Sign in Figure 1 (h) makes no sense at all. It is intended to remind us that the tap can provide water automatically as long as you reach out to it. So it should be Sensor Tap for short.

Actually, the transformation of linguistic dimension, communicative dimension and cultural dimension is not independent process. Ignorance on one of the 
dimensions will results in the failure of the other two dimensions. Equivalent translation to the original language only generates when all three dimensions integrated organically (Hu, 2004; Zhang, 2017).

\section{Conclusion}

With the development of local economy and tourism, the number of visitors to the Ten-mile liquor city will increase sharply. Besides providing fundamental guiding information, appropriate English translation of public signs meets the needs of the scenic area for a highly satisfactory language and cultural environment in its endeavor of building international cities and tourist destinations. To purify the language environment at the scenic area not only will facilitate the enhancing of the images of the city and the scenic area but also promote the communication of the liquor culture in Sichuan. In this paper the eco-translatology was adopted as the theoretical foundation to conduct the research on the English translation of public signs. Some inappropriate English translations of the public signs at the Ten-mile Liquor city are illustrated to enrich the discussion with the hope to rouse the attention of the administrative department. This article is also expected to attract more translators to participate in improving the English translation of public signs at the Ten-mile Liquor City.

\section{Funding}

This paper is supported by Research Center for International Transmission of Sichuan Liquor Culture (CJCB2017-03), Sichuan Provincial Department of Education (18SB0492), Sichuan Key Provincial Research Base of Intelligent Tourism (ZHYR18-02) and Industry Transformation and Innovation Centre of Zigong Social Sciences Association (CYZX2019-06).

\section{Conflicts of Interest}

The authors declare no conflicts of interest regarding the publication of this paper.

\section{References}

Chen, X. W. (2006). New Course Book on Pragmatic Translation. Beijing: Economy Science Press.

Dai, Z. X., \& Lv, H. F. (2005). On C-E Translation of Public Signs. Chinese Translators Journal, 6, 38-42.

Ding, H. Q. (2006). Improve Public Signs, Establish References. Chinese Translators Journal, 27, 42-46.

Guo, J. Z. (1998). Cultural Factors in Translation: Adaptation and Alienation. Journal of Foreign Languages, 2, 13-20.

Guo, J. Z., \& Xu, J. (1999). Contemporary Translation Studies in USA. Wuhan: Hubei Education Press.

He, X. Y. (2006). C-E Translation of Public Signs and Its Communicative Translation Strategy. Foreign Languages and Their Teaching, 3, 57-59. 
Hu, G. S. (2004). An Approach to Translation as Adaptation and Selection. Wuhan: Hubei Education Press.

Hu, G. S. (2008). Eco-Translatology: A Prime. Chinese Translators Journal, 6, 11-15.

Li, H. Y. (2018). C-E Translation of Public Signs in Wuliangye Ten-Mile Liquor City, Yibin. Open Access Library Journal, 5, e4579. https://doi.org/10.4236/oalib.1104579

Liu, F. G. (2008). Exploration on the Principles of C-E Translation of Public Signs. Foreign Languages and Their Teaching, 2, 47-50.

Luo, X. M. (2006). Translating Public Signs: Some Observations. Chinese Translators Journal, 4, 66-69.

Lv, H. F. (2017a). C-E Translation of Public Signs. Chinese Science \& Technology Translators Journal, 4, 38-40+64.

Lv, H. F. (2017b). Remarks on C-E Translation in the New Normal Context. Shanghai Journal of Translators, 4, 80-87.

Lv, H. F., Jiang, L., \& Zhou, J. B. (2015). On the Construction of a C-E/E-C Translation Corpus of Signs. Contemporary Foreign Languages Studies, 10, 48-55.

Xiong, B. (2014). Notion Confusion in Translation. Chinese Translators Journal, 3, 82-88. https://doi.org/10.1080/07374836.2014.887366

Zhang, X. L. (2017). On Public Sign Translation in Famous Scenic Spots of Henan Province from Perspective of Eco-Translatology. Journal of Chongqing University of Education, 3, 59-63. 